\title{
A COMPOSIÇÃO DA PROFESSORALIDADE SOB OLHARES MULTIRREFERENCIALIZADOS
}

THE COMPOSITION OF TEACHERALITY UNDER MULTI-REFERENTIAL VIEWS

\author{
Jussara Midlej
}

Universidade Estadual do Sudoeste da Bahia, Jequié, BA, Brasil. E-mail: jumidlej@uesb.edu.br

DOI: https://doi.org/10.46550/amormundi.v2i4.104

Recebido em: 08.03.2021

Aceito em: 18.04.2021

\begin{abstract}
Resumo: Artigo advindo de uma investigação-açáo educacional, realizada na primeira década do século XXI, envolvendo 37 professoras/alunas de um Curso de Licenciatura Plena em Educação Infantil e Séries Iniciais do Ensino Fundamental conveniado com a Secretaria Municipal de Educação de Vitória da Conquista e a Universidade Estadual do Sudoeste da Bahia. Aproximou-se de dimensóes cognitiva e estético-hermenêutica numa experiência ontológica, fenomenológica. $\mathrm{O}$ pluralismo metodológico da multirrefencialidade trouxe a natureza dialógica da linguagem em circunstâncias constitutivas de possíveis profissionais críticos. Visou a pesquisa e análises de como um processo, desta natureza, poderia provocar e ressignificar concepçóes acerca do trabalho pedagógico; de como se realizaria, nas escritas e nos diálogos a composição de suas professoralidades e possíveis reconceitualizaçóes de saberes da profissão. Demonstrou que registros e discussóes incitaram-nas a aguçar suas percepçôes, auxiliando-as a dilatarem processos de automonitoração impulsionando os entendimentos de si e das situaçôes pedagógicas.
\end{abstract}

Palavras-chave: Investigação. Formação. Linguagem. Práxis pedagógica.

Abstract: This is a paper resulting from an educational action research conducted in the first decade of the 21th century, over 37 teachers/students from a bachelor program in early childhood and primary education, in partnership with the Municipal Department of Education of Vitória da Conquista and Southwest Bahia State University. This work approached both the cognitive and esthetical-hermeneutical dimensions in an ontological, phenomenological experience. The methodological pluralism of the multireferenciality brought out the dialogical nature of language in constituent circumstances of eventual critical professionals. This work is intended to analyze the way in which such a process may provoke and give new meaning to conceptions concerning the pedagogical work; the way of composing their teacheralities through the texts and dialogues; and eventual reconceptualization of professional knowledges. It was demonstrated that records and discussions encourage them to sharpen their perceptions, helping them to expand the self-monitoring processes in order to boost the understanding of themselves and the pedagogical situations.

Keywords: Research. Formation. Language. Pedagogical praxis. 


\section{Consideraçóes iniciais}

[...] para qualquer pedagogia da diferença, são importantes o acontecimento, a linguagem, a intensidade do acontecimento, a contextualização da linguagem e seu sentido, a intertextualidade e a singularidade de seres ou grupos de seres. (SERPA, 2004, p. 157).

Anovas tecnologias, diversidade, participação social, multiculturalidade, integração escolar de pessoas com necessidades especiais, dentre outras, criaram renovadas demandas na linha de um ensino mais participativo; assim, indicam a necessidade de uma formação docente menos padronizada e conectada à racionalidade crítica, no sentido de diagnosticar obstáculos formativos e avançar para outros patamares filosóficos e políticos. (IMBERNÓN, 2007). Para além de diagnósticos e constataçôes, nunca é demais lembrar que muitos professores lidam, há muito, sem o devido preparo com suas próprias itinerâncias e os limites impostos pela própria condição humana e, ainda, com as vidas e os sonhos de seus alunos: de aceitação, de reconhecimento, de um futuro e de um mundo melhor, de uma sociedade mais digna, mais humana e mais fraterna.

No cerne do descrito contexto, a profissão docente traz, em si, desafios cotidianos de criação e recriação social, de saberes mais elaborados, de capacidades que respaldem os profissionais a lidar com as culturas nas suas diferenças, de modo a proporcionar aos alunos apreço aos valores e ideais coletivos, às buscas de soluçóes para os problemas de uma realidade complexa (MORIN, 2002) preparando-os para a autonomia de decisão, para a criatividade, para o mundo do trabalho. Nesses sentidos faz-se necessário que os estudantes sejam realmente transformadores da sua realidade e, assim, parece ser inevitável o papel ativo do docente no propiciamento de oportunidades de legitimação do conhecimento escolar e ampliação de concepçôes de vida e possibilidades multissetoriais.

\section{Contextualizaçáo}

[...] o reconhecimento intersubjetivo de exigências de validade, permite a formação de uma rede de interaçóes sociais e contextos do mundo, da vida. (HABERMAS, 1990, p. 297).

O encaminhamento coletivo da presente investigação-ação, entrecruzada por olhares multirreferencializados e relacionada à formação docente, ocorreu na primeira década do século XXI com professoras no desempenho de papéis docentes na educação básica e, concomitantemente, a atuarem como discentes de um Curso de Licenciatura Plena em Educaçáo Infantil e Séries Iniciais do Ensino Fundamental - modalidade de Curso Normal Superior. Este, fruto de um convênio realizado entre a Prefeitura Municipal de Vitória da Conquista e a Universidade Estadual do Sudoeste da Bahia (UESB). Este processo investigativo/formativo foi desenvolvido no âmbito da própria UESB e, ao mesmo tempo, nas classes das professoras partícipes, inicialmente atrelado a dois componentes curriculares ministradas por mim - Atividades de Articulação Curricular I e Psicologia do Desenvolvimento. Processaram-se em dois encontros semanais de cerca de 4 
horas/aula cada um; prosseguiu, em mais dois semestres, em encontros semanais com a mesma carga horária das demais disciplinas - Psicologia da aprendizagem e Pesquisa e prática docente I. O produto, construído paulatinamente e, a muitas mãos, resultou numa tese de doutoramento em Educação. Desse modo, a partir de uma liderança compartilhada, 37 professoras/alunas exerceram o papel de parceiras na produção e recolha de informaçóes.

Neste contexto, a maioria (59\%) declarou-se oriunda do município de Vitória da Conquista, na Bahia; as demais, oriundas e habitantes de municípios localizados no Sudoeste da Bahia. Da totalidade 100\% foram do sexo feminino, 59\% declararam-se pardas, 30\% brancas e $11 \%$ pretas. Houve uma predominância de 33\% das que possuíam de 30 a 34 anos sendo que $40 \%$ delas tinham de 11 a 15 anos de experiência docente e 33\% possuíam de 16 a 20 anos; 92\% estavam a atuar em classes iniciais do ensino fundamental e, apenas $8 \%$ na educaçáo infantil. Isso revela que elas eram pessoas experientes, não se apresentando um perfil de iniciante no magistério; As com menos tempo de serviço (24\%) tinham de seis a dez anos. O tempo de atividade na profissão foi um dado relevante: ele surgiu como um fator importante na compreensão dos saberes constituídos, já que o tempo de aprendizagem do trabalho confunde-se muitas vezes com o tempo de vida.

O estudo deu-se orientado por perspectivas epistemológicas/metodológicas de múltiplos referenciais e em concepçóes crítico-interpretativas de saberes da profissão e experiências do cotidiano escolar; desenvolveu-se na inter-relação de conjunturas individuais, sociais, políticas e institucionais, por meio de diálogos permanentes e revisão de conceitos tácitos, através de convocadas leituras acadêmicas e de constantes interlocuçóes e intervençóes nas realidades de suas classes. Portanto, de cunho crítico-emancipatória, esta açáo foi vivenciada como dialogicidade reflexiva e viabilizada por acordos comunicacionais propostos, tendo a natureza dialógica da linguagem (BAKHTIN, 1999) como viabilizadora de circunstâncias constitutivas de possíveis profissionais críticos. Sua realização justificou-se com a apresentação de contributos à produção crítica do conhecimento científico.

Assim sendo, a complexidade desta investigação/formação deu-se com um foco em açóes de linguagem (SMYTH, 1992) as quais são compreendidas como constitutivas de significaçôes de si, de outros, de contextos interacionistas sociodiscursivos; e, desse modo, "[...] como prática que se desenvolve em contextos reais carregada de intençóes e interpretaçóes subjectivas, construída por diversos atores e refletida em usos de natureza prática [...]"(SACRISTÁN, 1995, p. 79) e deram-se inter-relacionadas à espiral autorreflexiva de conhecimento e ação. (CARR; KEMMIS, 1988).

Como elementos tangenciais, as abordagens relacionadas a vidas de professores (NÓVOA, 1992) permitiram a vivência de um processo de articulação entre as vivências pessoais, a docência e a pesquisa. A ação, proposta e descrita, pode ser visualizada através da figura abaixo: 
Figura 1: $\mathrm{O}$ movimento investigativo-ativo e suas inter-relações

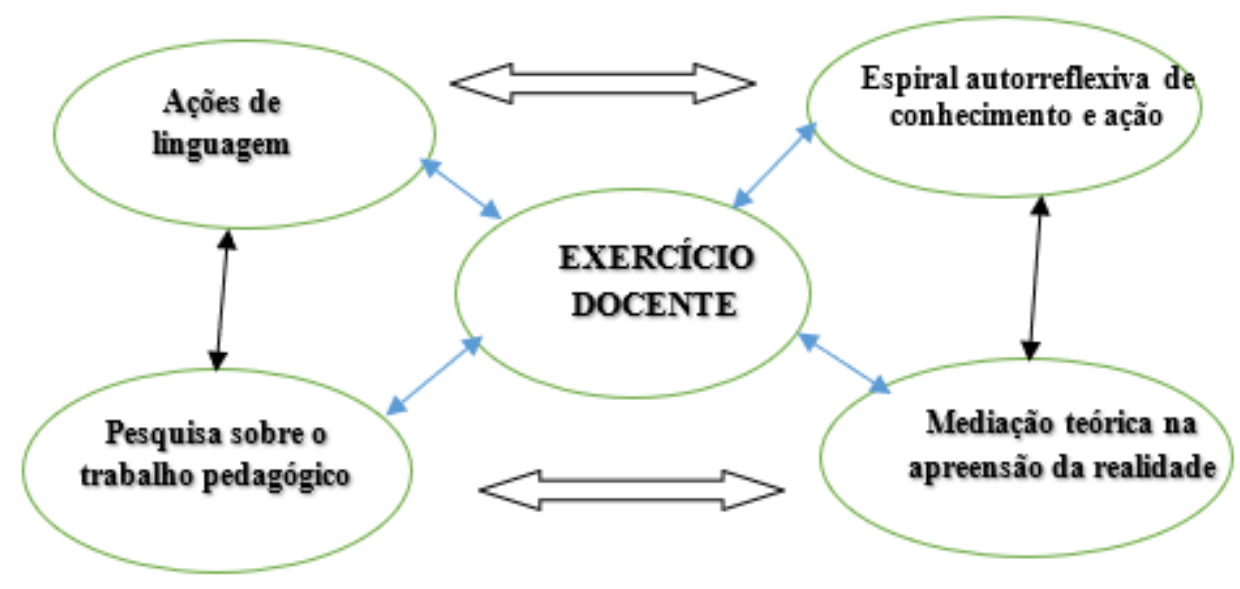

Esta, ao explicitar a operacionalização inter-relacionada, deste processo investigativo/ formativo, demonstra-o inserido num agir comunicativo (HABERMAS, 1989), a envolver aberturas para a compreensão de conceitos e experiências; nestas circunstâncias, deu-se com base no pressuposto de que é no discurso e pelo discurso que se elabora o conhecimento como significados e tensôes, tramas de criação e recriação de fatos, reconstrução de experiências e teorização da prática: fatores imprescindíveis ao escopo científico deste empreendimento, amplamente presentes. Os elementos epistemológicos e metodológicos, assim, ocorreram vinculados a ciclos sucessivos de práxis pedagógica - planejamento, ação, observação/reflexão e replanejamento de situaçóes pedagógicas tendo sido realizado na perspectiva de uma provável ampliação da sensibilidade socioexistencial do professor - como possível potencializador de consciências mais abertas, acerca da ação docente. (MIDLEJ, 2008).

Em tais dimensões, na sintonia com Carr e Kemmis (1988) manifestei, desde o primeiro momento, que a ação deveria se compor como concepção, e não, apenas, como uma modalidade de pesquisa tendo como objetivo aprofundar o conhecimento e acionamento de novas organizaçóes discursivas, análises críticas das práticas pedagógicas e de probabilidades de (re)construí-las em níveis mais complexos.

\section{Do elenco epistemológico às dimensóes metodológicas}

[...] a compreensão que se exerce nas ciências do espirito é essencialmente histórica, isto é, que também nelas um texto só é compreendido se for compreendido, em cada caso, de uma maneira diferente. (GADAMER, 1997, p. 461).

A espiral, vinculada a uma perspectiva emancipatória em vieses multirreferencializados (ARDOINO, 1998; BARBOSA, 1998; MAGALHÁES, 2002), adveio da espiral lewiniana, modificada por Carr e Kemmis (1988) e abriga, em si, "[...] uma sequência de fases, compondo ciclos sucessivos de planejamento, açáo e averiguação de fatos referentes ao resultado da ação.” (LEWIN, 1946, p. 22 - tradução nossa). Nesta, a possibilidade de formação de professores críticos-reflexivos, em dimensões praxiológicas. Sua operacionalização processou-se, desde o esclarecimento de uma dada situação, ao planejamento inicial de estratégias, atos de observação em locais de exercício de docências, compreensão, reflexão e, por fim, de um novo planejamento 
de açôes. Carr e Kemmis (op. cit, p. 202), acerca deste processo, asseveram: “[...] a investigaçãoação é participativa; é colaborativa quando grupos trabalham conjuntamente no estudo de sua própria práxis individual e quando estudam as interaçôes sociais entre elas [...].” O quadro abaixo explicita as fases e as açóes desta espiral:

Quadro 1: Espiral autorreflexiva de conhecimento e ação

- Aclarar e diagnosticar uma situação prática; (diagnósticos realizados no contexto escolarvisando organizar intervençóes).

- Formular estratégias de ação; (formulação e realização, individuais, de planos de ação didática).

- Desenvolver estratégias e avaliar sua eficiência; (observação, análise e desenvolvimento desituaçóes pedagógicas).

- Ampliar a compreensão da nova situação; (açóes de linguagem acerca da realidade doplanejamento e da prática: socializaçáo dos registros, teorização da prática).

- Proceder os mesmos passos para a nova situação prática; (produção dos mesmos passos paranovas conjunturas).

Fonte: (CARR e KEMMIS, 1988).

Conforme se pode analisar, a linguagem funcionou como mediadora das atividades sociais, tendo sido acionada permanentemente, numa dinâmica reflexiva, crítica; o interrelacionamento das açóes linguístico-discursivas, com a concepção, serviu como referência para organizar as sessóes reflexivas que se iniciaram com as negociações visando a minha permanência, intencionada, sistematizada e prolongada, no campo acadêmico e acompanhamento das açóes docentes, através de registros. Nas negociaçóes utilizei-me das ideias de Bakhtin (1999) referentes à criação de condiçôes para uma compreensão responsiva ativa, onde as pessoas, ao concordarem ou discordarem de situaçóes propostas referendam, complementam, posicionando-se. Assim, ao lado da observação participante ativa ocorreram debates e registros de notas pessoais, nos diários reflexivos, como memória ativa descritiva (ANDRÉ; LÜDKE, 1986) aliados ao emprego de um questionário semiestruturado, socioantropológico e processos de escuta sensível (BARBIER, 2002) operacionalizados em vieses diagnósticos.

Nos modos descritos, na condição de mediadora acadêmica, eu tinha consciência de que, tais referências, ao se encontrarem ligadas ao paradigma da complexidade (MORIN, 2002) requeriam um trabalho dialógico e multidimensional, no qual ligar e problematizar caminhariam juntos nas sessôes reflexivas. Assim, a vivência dæspiral deu-se, a partir de processos reflexivos intencionais, anunciados, negociados, sistematizados e sintonizada a movimentos que indicaram a necessidade de reatamentos, revisão de valores humanos, de reforma das estruturas de pensamento, de formação de pessoas mais interativas, autônomas. Foram empregados procedimentos e estratégias metodológicas a exemplo de: narrativas de fragmentos de histórias de vida, inclusive pedagógicas, como reapropriação do universo sociocultural; descrição e interpretação de realidades discentes e docentes; definição de experiências e de construção de maneiras de ser e estar na profissão. (DELORY-MOMBERGER, 2000; DOMINICÉ, 2000).

Assim, ocorreram sessôes reflexivas com interaçóes face a face em dois encontros acadêmicos, semanais, com duraçáo de 4 horas/aula, cada um envolvendo trabalhos sistematizados com as leituras realizadas a priori, a operacionalização da espiral autorreflexiva de conhecimento e ação com diagnósticos de situaçóes, planejamento; atuação; investigação; reflexão; socialização; teorização da prática; ressignificação; (re)planejamento de cenas pedagógicas; (re)ajustes de açôes 
às necessidades individuais e coletivas; organização das açôes de linguagem visando criar contextos de compreensão dos significados epistemológicos de suas escolhas didáticas, os interesses que as servem, concepçóes a que estão atreladas.

Tais estratégias e instrumentos constituíram-se como elementos fundantes na articulação entre a investigação-ação, a docência e a formação na condição de pontos nucleares - nos conhecimentos teóricos e na discussão da prática educativa - em direção ao conhecimento da realidade. Proporcionaram, além de um relacionamento com os citados elementos epistemológicos, uma investigação didática e de intervenção das partícipes, sobre as situaçóes problemáticas, tanto na condição de alunas, quanto na de professoras.

Em tais sentidos, os critérios de validade científica, ao serem substituídos por critérios de rigor metodológico de credibilidade, transmissibilidade, de fiabilidade e de confirmaçáo de dados - definidos por Guba e Lincoln (1985) - tiveram como implicação não apenas o vigor de minha presença com as parceiras, como também as destas nos locais onde se davam suas docências. Desse modo, o conteúdo das práticas docentes e pressupostos críticos, crenças e valores subjacentes a elas (ELLIOT, 1993) ao serem trazidos para as sessóes reflexivas forneceram subsídios à espiral e às açôes de teorização da prática, enriquecendo, sobremaneira a atividade acadêmica.

Com tudo isto ampliei os subsídios para que a checagem dos elementos fossem confrontados com diversos pontos de vista, apoiados numa variedade de informaçóes e na busca de valores que se encontravam subjacentes às comunicaçôes. E, ainda: comparando as interpretaçóes dadas, ao mesmo fenômeno, instiguei as descriçóes de fatos, ancorados nas realidades e na dinâmica acadêmica, na perspectiva de compreender/descrever as diversas situaçôes observadas. As descriçóes, densas, ajudaram-me a estruturar o quadro configurativo da investigação e encaminharam minhas pautas de observação, também, na direção de inferências: com o cuidado para não cair num empirismo vazio busquei os movimentos que se configuraram na dinâmica das interaçóes que refletiam os valores, as crenças, os pressupostos que se encontravam subjacentes às práticas pedagógicas.

O processo de impregnação (MACEDO, 2006) realizou-se através de leituras dos diários reflexivos no sentido de detectar as marcas e as dimensóes mais relevantes das informaçóes que constituíram-se como valiosas na estratégia da triangulação. Com isso, numa primeira síntese surgiram as dimensões conceituais para a organização do trabalho analítico, no qual a análise de conteúdos foi utilizada como "[...] um recurso metodológico, interpretacionista, visando descobrir o sentido das mensagens das situaçóes comunicativas.” (Op. cit., p. 145). E, assim, se deu, a partir da compreensão dialógica bakhtiniana, (BAKHTIN, 1988) integrarem enunciado e vida, falante e ouvinte, linguagem e consciência na composição da professoralidade. (PEREIRA, 2001, 2013).

\section{Composição da professoralidade}

[...] voltar sobre os próprios passos, para encontrar outras possibilidades de continuar em movimento... (CORAZZA 2002, p. 106-107).

O conhecimento dos professores, ao comportar um conhecimento pedagógico específico, denota que, o que se está sendo, quando se é professor, é um componente atualizado de 
diferentes possibilidades históricas e culturais que se circunscrevem e se atualizam em inúmeras possibilidades a perfazerem o campo da subjetividade. (PEREIRA, 2001). O autor denomina tal processo de professoralidade, enunciando: "Vir a ser professor é uma diferença, de si, que o sujeito produz culturalmente (num campo coletivo) num dos seus inumeráveis movimentos de ser no mundo." (Op. cit., p. 23 -24). Ele busca, com isso, “[...] explicitar caminhos nos processos de formação, que contribuam para considerar a inseparabilidade da (auto)formação profissional e produção da subjetividade." (P. 38). Fundamenta-se em Deleuze (1988), Deleuze e Guattari (1995), Foucault (1994), para a identificação dos modos e possibilidades de interferir nos fluxos de atualização do devir professor, na processualidade que compóe tais fluxos.

Ao tomar como referência as produçóes epistêmicas de Pereira $(2001$; 2013) operei na direção da constituição subjetiva da profissão por compreender que o citado processo, a partir da de sua concepção encontra-se "[...] abalado por uma tensão desestruturante, a experimentar o caos das forças interferentes e se organiza em uma nova forma existencial” (2001, p. 39) em direção contrária ao movimento identitário que assume uma “[...] configuração cristalizada de uma forma de ser." (p. 36). Ao operar com estes conceitos presumi, a exemplo deste autor (p. 32), "[...] que a escolha de ser professor passa, necessariamente, pela reconstituição de alguns fatos que antecedem essa decisão." Nesse caso, “[...] a nova composição será uma recomposição, obedecendo aos modos dominantes de estratificação [...]. (PEREIRA, 2013, p. 36). Suas ações, ao se assentarem num corpo de significados, assim, podem ter sua gênese nas experiências vividas ao longo da vida, em especial na condição de discentes. A escrita autobiográfica, ao fertilizar retornos, de si para si mesmas, foi adotada como um método privilegiado de se ter acesso ao universo "[...] de uma formação existencial singular, [...] em constante iminência de deixar de ser o que vem sendo para tornar-se diferente de si mesmo [...]." (PEREIRA, 2001, p. 34). $\mathrm{E}$, ainda visando favorecer a mobilização das estruturas tácitas de pensamento e ampliação de conhecimentos. Houve, desse modo, uma intencionalidade de reconstituição passando pela "[...] condiçáo humana, em sua processualidade [...] no sentido de explicitar caminhos de formação.” (Op. cit. p. 38).

Nesses sentidos, a narrativa autobiográfica funcionou como um lugar de reconstrução de saberes ao dar acesso ao universo "[...] de uma formação existencial singular, [...]." (Op. cit., p. 34). Este procedimento, ao apresentar indícios de contribuir para uma revisitação ao passado, tal como ele submergiu, funcionou como um fio condutor do conjunto de forças, (FOUCAULT, 1993), das experiências e partilhas: seus registros, socializados, enriqueceram as discussóes teóricas nas sessóes reflexivas ajudando-as a analisar aspectos relacionados ao processo de ensino e aprendizagem vivenciados, ao longo da vida, por elas. Assim, compuseram as rememoraçôes nas famílias, nas escolas e ampliaram a sistematização de conhecimento vinculadas a aportes epistemológicos, explorados.

\section{Informaçóes recolhidas e dimensóes analíticas}

Pode-se lá, porém, permitir que a palavra nasça do amor da gente, assim, de broto e jorro: ai a fonte, o miriquilho, o olho d'água; ou como uma borboleta sai do bolso da paisagem? (GUIMARÃES ROSA, 1967, p. 66).

Esta ação, ao estar vinculada à situação acadêmica por três semestres letivos, trouxe consigo a instauração de um diálogo fecundo entre a pesquisa acadêmica e a prática pedagógica. Nesse 
contexto, o uso do diário reflexivo foi realizado como instrumento de investigaçáo didática e reflexão acerca das ações, através de registros escritos das próprias práticas educacionais.

Nessa trajetória, havia uma consciência, de minha parte, de que a caminhada investigativa não deveria apenas interpretar a realidade, mas ao mesmo tempo, abrir possibilidades de desenvolver-se como princípio científico e educativo. Assim, a experiência de projetar e discutir os contextos rompia com a lógica de formação, tradicionalmente, vivenciada: não se tratava mais de estudar uma teoria a ser aplicada a posteriori, mas de, a partir da consciência do que se estava a realizar, promover articulaçóes teoria-prática e prováveis reformulaçóes de concepçóes e estratégias docentes. Os discursos, entrelaçados em ações comunicativas sistemáticas - porque baseados nas narrativas dos diários e expressos em comunicações verbais - foram abordados a partir da hermenêutica gadameriana " [...] onde avida humana é concebida como um horizonte de possibilidades náo decididas [...] antes, condicionada e contextualizada pelo fenômeno da linguagem, da cultura e da política."(GRÜN; COSTA, 2002, p. 96 - 97). Do mesmo modo, o enfoque fenomenológico conferiu, a este estudo, como um elemento de produção de sentidos, atitudes de abertura a orientaçóes originárias de literatura acerca de concepçóes analíticas que têm, como fio básico, a linguagem e, daí, encontrarem-se marcadas pelo dialogismo interacional "[...] como um tecido de muitas vozes que se entrecruzam, se completam, respondem umas às outras, ou polemizam entre si e no interior do texto." (BRAIT, 1997, p. 34).

Assim, o trabalho com a linguagem vinculou-se às características linguístico-discursivas de cada uma das açôes que compóem o processo reflexivo sistematizado: descrever, informar, confrontar e reconstruir. Destes dispositivos foram feitas leituras densas e elaboração de quadros configurativos de aprofundamento de mensagens implícitas: eu fazia anotaçóes à margem dos relatos, dialogando por escrito, concitando-as a desestabilizarem os conhecimentos prévios e a desenvolverem olhares sobre as questôes que as instigavam. Tais açóes me possibilitavam dar retornos com um referencial teórico mais próximo das necessidades sentidas.

Nessa acepção, os registros funcionaram como dispositivos mediadores (ALTET, 2001) e ocorreram como procedimentos científicos de construção de conhecimento e como processo formativo, no entrelaçamento entre formação, pesquisa e o exercício da profissão propiciando maiores envolvimentos entre as pessoas e enriquecimento do exercício hermenêutico. À medida que esse processo ia se desenvolvendo, novos conhecimentos, acerca da prática pedagógica, eram produzidos "[...] trazendo a marca do provisório, do inacabado, passíveis de serem transformados, ou até mesmo refutados.” (DICKEL et al., 2007, p. 39). Análises se seguem, oriundas das informaçóes colhidas, aleatoriamente, nos 37 diários reflexivos.

\section{Registros e análises}

Somos irremediavelmente parte daquilo que analisamos e que tantas vezes, queremos modificar. (VEIGA-NETO, 2002, p. 36).

O processo de formação, aliado à investigaçáo, ao instigar as pessoas a escreverem sobre suas experiências deu mostras de cumprir o desafio de promover aprendizagens vinculadas à realidade contextual. Embora as resistências iniciais, aos poucos, mesmo aquelas que relutavam foram criando o hábito de anotar intenções e registros, açôes pedagógicas. Nos momentos de socialização liam-nas, revelando percepóes/ações. Desde o início já se podiam ver registros como 
estes:

Escrever no diário reflexivo é bom, preciso reconhecer, pois nos leva à autoavaliação e daí surge questionamento (sic): será que estou no caminho certo? Em que posso melhorar? A minha prática condiz com a teoria e vice-versa? [...] após o diário vejo que estou me tornando mais crítica e exigente [...]. (BV).

Numa semana de escrita de minhas açôes no diário reflexivo vejo que isto vem contribuindo para a minha transformação e passei a gostar mais de escrever. (SG).

Transparece, aqui, a reflexão como componente essencial da análise que une pensamento e ação como investigação e, esta, quando colocada no mesmo nível da responsabilidade intelectual demonstra gerar uma categoria apontada por Dewey (1979, p. 44), na experiência da produção de saberes interligada à práxis: "Ser intelectualmente responsável quer dizer considerar as consequências de um passo projetado; significa ter vontade de adotar essas consequências [...]." Em processos metacognitivos e metapráxicos, ela dá mostras de potencialização de compreensôes das situaçóes reais a demonstrar que os atos de interlocução, consigo mesmas, traz o que Bakhtin (1999) chama de compreensão responsiva ativa: ao se questionar e às situaçôes, a professora-aluna $\mathrm{BV}$ referenda o uso do instrumento, posicionando-se ao dizer-se mais crítica e exigente. Ficam patentes reaçóes, acerca dos fatos da realidade: abaixo, um exemplo relacionado às vivências das açóes de linguagem vinculadas à espiral. Trata-se de uma cena pedagógica, das realizadas, escolhida aleatoriamente. Para facilitar as transcrições se deram no interior de um quadro analítico criado, por mim, para esta finalidade:

Quadro 2 - Transcrição da cena pedagógica I - inter-relacionada às Açôes de linguagem e à Espiral autorreflexiva de conhecimento e ação.

\begin{tabular}{|c|c|c|c|}
\hline $\begin{array}{l}\text { UNIDADES SIGNI- } \\
\text { FICATIVASINVES- } \\
\text { TIGADAS }\end{array}$ & $\begin{array}{l}\text { REGISTROS DA PROFES- } \\
\text { SORA-ALUNA EG }\end{array}$ & $\begin{array}{l}\text { AÇÓES DE } \\
\text { LINGUAGEM }\end{array}$ & $\begin{array}{l}\text { ESPIRAL AUTOR } \\
\text { REFLEXIVA }\end{array}$ \\
\hline $\begin{array}{c}\text { Saberes e experiên- } \\
\text { cias docentes como } \\
\text { prováveis aciona- } \\
\text { doras de renovadas } \\
\text { percepçóes e organi- } \\
\text { zaçôes discursivas. }\end{array}$ & $\begin{array}{l}\text { Em classe vejo problemas com } \\
\text { a leitura e a escrita: levei alguns } \\
\text { poemas e li-os para os alunos, } \\
\text { procurando chamara atenção de- } \\
\text { les para esta modalidade de texto. } \\
\text { Fiquei frustrada porque vi que } \\
\text { eles nấo se interessaram muito } \\
\text { por estas. Fui pensar no que fa- } \\
\text { zer para buscar o interesse deles e } \\
\text { torná-la interessante. Lembrei das } \\
\text { leituras que fiz sobre as teorias de } \\
\text { Piaget e Vygotsky. }\end{array}$ & $\begin{array}{l}\text { DESCREVER } \\
\text { (O que fiz?) } \\
\text { (O que faço?) } \\
\text { (Foco do } \\
\text { processo } \\
\text { reflexivo). }\end{array}$ & $\begin{array}{l}\begin{array}{l}\text { Diagnóstico de uma } \\
\text { situaçáo prática; }\end{array} \\
\text { Planejamento; } \\
\text { Formulaçáo de estra- } \\
\text { tégias de ação. }\end{array}$ \\
\hline $\begin{array}{l}\text { Questionamen- } \\
\text { to e superação } \\
\text { de concepçôes e } \\
\text { açóospedagógicas } \\
\text { monossêmicas e } \\
\text { mecanicistas. }\end{array}$ & $\begin{array}{l}\text { Vejo que devemos trabalhar } \\
\text { de uma forma que elimine a } \\
\text { simplestransmissáo de conhe- } \\
\text { cimentos e motivar a criança a } \\
\text { construir e reconstruir hipóteses } \\
\text { sobre o mundo. }\end{array}$ & $\begin{array}{l}\text { INFORMAR } \\
\text { (O que } \\
\text { issosigni- } \\
\text { fica) } \\
\text { (Foco nos } \\
\text { conceitos que } \\
\text { perpassam as } \\
\text { açôes). }\end{array}$ & $\begin{array}{l}\text { Avaliação da } \\
\text { eficiência das } \\
\text { estratégias em- } \\
\text { pregadas; } \\
\text { Teorização da } \\
\text { prática; } \\
\text { Formulação de } \\
\text { outras formas de } \\
\text { ação possíveis e } \\
\text { suas razóes. }\end{array}$ \\
\hline
\end{tabular}




\begin{tabular}{|c|c|c|c|}
\hline $\begin{array}{l}\text { (Re)construção } \\
\text { de conhecimentos } \\
\text { didáticos e pedagó- } \\
\text { gicos em níveis mais } \\
\text { elevados de critici- } \\
\text { dade. }\end{array}$ & $\begin{array}{l}\text { Vi que precisava entrar no } \\
\text { conteúdo a partir da realidade } \\
\text { deles, a fim de ver se chamava a } \\
\text { atençáo dos alunos. } \\
\text { Pensando nisso, tive uma idéia. }\end{array}$ & $\begin{array}{l}\text { CONFRONTAR } \\
\text { (Como ajo?) } \\
\text { (Foco na } \\
\text { avaliação e } \\
\text { percepção da } \\
\text { situação). }\end{array}$ & $\begin{array}{l}\text { Investigação } \\
\text { Reflexão; } \\
\text { Desenvolvimento de } \\
\text { novas estratégias; } \\
\text { Compreensão da } \\
\text { situação. }\end{array}$ \\
\hline $\begin{array}{l}\text { Desenvolvimento } \\
\text { de uma sensibilida- } \\
\text { de socioexistencial } \\
\text { e histórica das pes- } \\
\text { soas. }\end{array}$ & $\begin{array}{l}\text { A partir daí chamei-os pra brin- } \\
\text { car de "chuva de palavras" (cada } \\
\text { um dizia uma palavra e eu ia } \\
\text { anotando no quadro). Em segui- } \\
\text { da estas palavras serviram de base } \\
\text { para a criação de um poema cole- } \\
\text { tivo e o envolvimento de todos se } \\
\text { deu de modo positivo. } \\
\text { Cada um trouxe a sua contri- } \\
\text { buiçáo ese deram momentos de } \\
\text { muita aprendizagem. } \\
\text { Pude trabalhar com eles os } \\
\text { conceitos de verso, estrofe e } \\
\text { rimas e explorei ao máximo o } \\
\text { significado do poema que teve } \\
\text { como tema A PAZ. No fim eles } \\
\text { fizeram questáo de copiá-lo nos } \\
\text { cadernos. Vou realizar mais ati- } \\
\text { vidades desse tipo. }\end{array}$ & $\begin{array}{l}\text { RECONSTRUIR } \\
\text { (Como } \\
\text { possoagir } \\
\text { de modo } \\
\text { diferente, } \\
\text { renovado?) }\end{array}$ & $\begin{array}{l}\text { Novas reflexóes } \\
\text { sobre a prática; } \\
\text { Replanejamento } \\
\text { de cenas peda- } \\
\text { gógicas; } \\
\text { (Re)ajuste de } \\
\text { açóes; } \\
\begin{array}{l}\text { Desenvolvimento } \\
\text { de novas estraté- } \\
\text { gias; }\end{array} \\
\text { Processamento de } \\
\text { etapas semelhantes } \\
\text { para a nova situação } \\
\text { prática. }\end{array}$ \\
\hline
\end{tabular}

Desses modos, a práxis educacional, se deu aliada a um agir epistêmico metacognitivo e transparece, no quadro, como uma ação exercida na condição de diálogo contrapondo-se a modelos tradicionais de educação. Embora explícitos, estes juízos pessoais são, por seu próprio caráter, sempre discutíveis e devem estar abertos a reinterpretaçóes, através da prática reflexiva e, não, em relação a pontos imutáveis. (PEREIRA, 2001, 2013). Nesses sentidos, EG, ao deixar transparecer, no diário, a gestão da situação pedagógica exerceu a pesquisa como algo cotidiano, com informaçóes colhidas na realidade e seleção de indicadores que a auxiliaram a interpretar os sinais, utilizá-los para as decisôes. Ao afirmar que "vou procurar realizar mais atividades desse tipo [...]", ela exterioriza a força que possuem os dados empíricos fundamentando uma melhoria do trabalho docente. É um fato que, na reconstrução das açôes expressas e, com a ajuda de dispositivos mediadores (ALTET, 2001, p. 33), as condutas auto-observáveis passam por um processo de pensar sobre o próprio pensar, dirigido por operaçóes mentais complexas que as afastam do automatismo. Assim, a atuação parece se ligar aos julgamentos, a partir de seus registros. Desse modo, através da articulação entre o mundo vivido e o sistema social, o homem 
se constrói. (BENASSULY, 2002).

$\mathrm{Na}$ vivência de um processo que se modifica em espirais de reflexão e ação, permeado por mediações, pode-se observar, a partir do exemplo trazido, que nem sempre é fácil para o docente deslocar-se de um modelo que lhe é familiar para outro. Ao levar-se em conta o procedimento descrito, a professora, em pauta, diagnosticou, no ato, a ineficácia de sua ação; lembrou, embora de modo superficial, de leituras realizadas e definiu-se por formular outras estratégias didáticas. Ao desenvolvê-las, utilizou-se de instrumentos conceituais, ainda em processo de acomodação dentro de si transformando-os em saber adaptado à situação: agiu de modo diferente. "Esta articulação entre saberes e adaptação na ação ocorre implicitamente e requer uma reflexão do profissional sobre seus atos." (ALTET, 2001, p. 31). Assim se deu: o ato reflexivo, ao se centrar na análise do que foi realizado, apresentou-se marcado por probabilidades de ampliar o olhar para a práxis educacional como algo, sobre o qual, ela podia pensar e o fez. Assim, EG, ao confrontar-se com a situação avaliou-a, deu mostras de visualizar outras formas de ação, realizando-as. Percebese que a linguagem da reflexão crítica instrumentalizou-a para a transformação ajudando-a a definir novas estratégias, outras possibilidades de docência. Ressalto o entendimento que EG, ao empreender seus registros, refletiu e ampliou suas compreensôes para as premissas teóricas que sustentam as práticas: as situaçóes constituíram-se como pontos de partida e deram-lhes condiçôes para mudar a qualidade de suas tarefas. É preciso reconhecer, entretanto, que ainda há uma distância entre estes fatos e o empreendimento de mudanças em seus percursos. Atente-se para a infraestrutura tácita do conhecimento, presente no sistema cognitivo das pessoas adultas e que trazem, em si, aportes de cristalização em torno do que é familiar à mente levando-a "[...] a defender-se de tudo o que lhe prometa perturbar os seus próprios balanços e equilíbrios." (BOHM; PEAT, 1989, p. 36). Apresento, abaixo, a transcrição de um registro colhido no diário reflexivo da professora-aluna BS. Suas palavras confirmam o que vem sendo dito:

Depois que estou frequentando este Curso, já senti uma diferença em minha prática. Agora me interesso mais por analisar e refletir sobre as açóes tentando melhorá-las. Ainda assim, tenho dificuldades e não posso dizer que a mudança é total, não é fácil mudar, na idade em que estou: acho difícil trabalhar com alguns conteúdos que não seja de modo tradicional. Mas sei o quanto este processo vem me ajudando: hoje escuto mais os alunos valorizo a opiniáo de cada um e faço com que eles possam interagir mais. Agora eu reconheço o valor da teoria e procuro ler. É uma pena que o tempo não dê para me aprofundar nos estudos como eu preciso... (BS).

Aqui está, explícita, a disposição para a mudança, embora a professora reconheça-a como difícil demonstrando que tem problemas na mobilizaçáo de seus conhecimentos para outras concepçóes. Ao trazer a dificuldade de exercer a docência de um modo que não seja o tradicional, anuncia que o processo ajudou-a a escutar os alunos, valorizá-los, colocá-los em interação. Diz das condiçóes sociais em que vive: a falta de horário para a sistematização de estudos, além de dar visibilidade para a sobrecarga de trabalho - a se constituir em barreira para a organização da ação docente. 


\section{Consideraçóes finais}

\section{Erramos quando acreditamos nos fatos: só há signos. Erramos quando acreditamos na verdade: só há interpretaçôes. (DELEUZE, 2003, p. 86).}

A tarefa acadêmica, nesses moldes, deu indícios de trazer perspectivas de acréscimo da compreensão epistemológica e metodológica dos componentes fundantes da ação docente, embora tenha apresentado sinais de tensão na (re)criação de percepções, fatos, (re)construção de experiências e teorização da prática.

Em tais vieses, os registros realizados, ao trazerem à pauta a polissemia da linguagem usada na perspectiva das dimensôes cognitiva e estético-hermenêutica, como produçôes sociais enriquecedoras - produziram fluxos de informação e movimentos que pareceram impulsionar construçôes de caráter crítico-emancipatório da práxis pedagógica; as informações recolhidas e analisadas asseveram que, nas condições dadas, inquietaçôes epistemológicas vieram à tona e problematizaram a relação ensino/aprendizagem, auxiliando as partícipes a vivenciar processos de desacomodação, desestabilização, com o que acreditavam ser válidos para suas açóes docentes, até entâo. Assim, registro que, muito embora num contexto de precárias condiçôes formativas e profissionais, onde ações conjugadas de trabalho, salário e formação demonstraram dificultar exercícios crítico-reflexivos da profissão, aconteceram inquietaçóes e incipientes atos de desfamiliarização de concepções tradicionais com as quais, estas, antes se expressavam, acerca da vida e da ação profissional. Verifiquei, assim, especialmente através das ações de linguagem que, mesmo sob uma conjuntura perversa, o exercício formativo/investigativo possibilitou construçóes mais conscientes e distantes do puro automatismo de práticas consolidadas, o que auxiliou, sobremaneira, embrionárias atuações docentes mais críticas e emancipatórias.

Com base em tais assertivas ratifico as evidências de que a instância acadêmica, voltada para a especificidade da docência, demonstra-se carente de promover, dentre inúmeras outras questóes, posturas autorreflexivas, interculturais e poéticas que deem condiçóes ao professor de potencializar aberturas do ser para a lida com as grandes tensôes que envolvem a profissão; o processo vivido aponta, assim, para necessidades de açóes promotoras de reconceitualização de saberes, revisóes de atitudes profissionais que possam gerar concepçóes de ensino e aprendizagem ativas, interativas, inventivas. Nesses sentidos, que possam envolver processos de autoconhecimento e automonitoração visando dilatar a composição da professoralidade para dimensôes mais abrangentes e afins com posturas que falem da fluência da vida e de renovadas formas de pronunciá-la.

\section{Referências}

ALTET, Marguerite. As competências do professor profissional: entre conhecimentos, esquemas de ação e adaptação, saber analisar. In: PERRENOUD, Philippe et al. Formando professores profissionais. Que estratégias? Quais competências? 2. ed. Tradução de Fátima Murad e Eunice Gruman. Porto Alegre: Artmed, 2001, p. 23 - 35.

ANDRÉ, Marli André; LÜDKE, Menga. Pesquisa em educação. Abordagens qualitativas. São Paulo, EPU. 1986. 
ARDOINO, Jacques. Abordagem multirreferencial (plural) nas situaçōes educativas e formativas. In:BARBOSA, Joaquim. (Org). Multirreferencialidade nas ciências e na educação. São Carlos: EdUFSCar, 1998, p. 24-41.

BAKHTIN, Mikhail. Questôes de literatura e de estética: a teoria do romance. Tradução de Aurora F. Bernardini. São Paulo:UNESP/HUCITEC, 1988.

BARBIER, René. A Pesquisa-ação. Tradução de Lucie Didio. Brasília: Plano, 2002.

BARBOSA, Joaquim. (Org). Multirreferencialidade nas ciências e na educação. São Carlos: EdUFSCar, 1998.

BENASSULY, Jussara S. A formação do professor reflexivo e inventivo. In: LINHARES, Célia. LEAL, Maria Cristina. (Org). Formação de professores: uma crítica à razão e à política hegemônicas. Rio de Janeiro: DP\&A, 2002, p. 185 -195.

BOHM, David; PEAT, F. David. Ciência, Ordem e Criatividade. Tradução de Jorge da Silva Branco. Lisboa: Gradiva. 1989.

BRAIT, Beth. Bakhtin e a natureza constitutivamente dialógica da linguagem. In. (Org). Bakhtin, dialogismo e construção do sentido. Campinas, SP: Editora da UNICAMP, 1997, p. $91-104$.

CARR, Wilfred.; KEMMIS, Stephen. Teoria crítica de la enseñanza: la investigación-acción en laformación del profesorado. Barcelona: Ediciones Martinez Roca, 1988.

CORAZZA, Sandra Mara. Labirintos da pesquisa, diante dos ferrolhos. In: COSTA. Marisa. Vorraber. (Org.) Caminhos investigativos. Novos olhares na pesquisa em Educação. São Paulo: DP\&A editora. 2002, p. 105-131.

DELEUZE, Gilles. Diferença e repetição. Tradução de Luiz Orlandi e Roberto Machado. Rio de Janeiro:Graal, 1988.

DELEUZE, Gilles. Proust e os signos. Tradução de Antônio Piquet e Roberto Machado. Rio de Janeiro: Forense universitária, 2003.

DELEUZE, Gilles \& GUATTARI, Félix. Mil Platôs - Capitalismo e

Esquizofrenia. Tradução de Aurélio Guerra Neto et alii. 01. Rio de Janeiro: Editora 34, 1995.

DELORY-MOMBERGER, Christine. Les histoires de vie. De l'invention de soi au profet de formatin. Paris. Economica, 2000.

DEWEY, John. Como pensamos. Como se relaciona o pensamento reflexivo com o processo educativo. Uma reexposição. 3. ed. Tradução e notas de Haidée de Camargo Campos. São Paulo: Companhia Editora Nacional, 1979.

DICKEL, Adriana. et al. Professores pesquisadores como produtores de conhecimento. In: VARANI, Adriana. FERREIRA, Cláudia Roberta; PRADO, Guilherme do Val Toledo. Narrativas docentes. Trajetórias de trabalhos pedagógicos. Campinas: Mercado de Letras, 2007, p. 29-42.

DOMINICÉ, Pierre. Histoire de vie comme processus de formation. Paris: L'Harmatan, 2000. 
ELLIOT, John. El cambio educativo desde la investigación-acción. Madrid: Morata, 1993.

FOUCAULT, Michel. Microfisica do poder. 11.ed. Tradução Roberto Machado. Rio de Janeiro,Graal, 1993.

FOUCAULT, Michel. Marxismo e Filosofia da linguagem. 9. ed. Tradução de Yara F. Vieira Lahud. São Paulo: Hucitec, 1999.

GADAMER, Hans. G. Verdade e Método. Traços fundamentais de uma hermenêutica filosófica.2 ed. Tradução de Flávio Paulo Meurer. Petrópolis, RJ: Vozes, 1997.

GRÜN, Mauro.; COSTA, Marisa Vorraber. A aventura de retomar a conversação: hermenêutica e pesquisa social. In: COSTA, Marisa Vorraber. (Org.). Caminhos investigativos: novos olhares da pesquisa em educaçáo. Rio de Janeiro: DP\&A, 2002. p. 85-104.

GUBA, Egon. LINCOLN, Yvonna. Naturalistic inquiry. Beverly Hills: Sage, 1985.

HABERMAS, Jürgen. Consciência moral e agir comunicativo. Tradução de Guido A. de Almeida. Rio de Janeiro: Tempo Brasileiro, 1989.

HABERMAS, Jürgen. O discurso filosófico da modernidade. Lisboa: Portugal. Publicaçôes D. Quixote, 1990.

IMBERNON, Francisco. Uma nova formação docente. In: Pátio. Revista pedagógica. Ano X. N. 40. Nov2006/Jan 2007, p. 13-15.

LEWIN, Kurt. Action research and minority problems. In: Journal of social Issues, 2. 1946, p. $34-46$.

MACEDO, Roberto Sidnei. Etnopesquisa crítica, etnopesquisa formação. Brasília: Liber Livro Editora, 2006.

MAGALHÃES, Maria Conceição C. Sessões reflexivas como uma ferramenta aos professores para a compreensão crítica das ações da sala de aula. Trabalho apresentado no $5^{\circ}$ Congresso da Sociedade Internacional para Pesquisa Cultural e Teoria da Atividade. Amsterdam: Vrije Univesrsiteit. 18-22 jun, 2002.

MIDLEJ Jussara. A investigação-ação educacional e as ações de linguagem como princípios formativos do ser professor. 2008, $281 \mathrm{f}$. Tese (Doutorado em Educação). Faculdade de Educação. Universidade Federal da Bahia (UFBA). Salvador, Bahia. Abril, 2008.

MORIN, Edgar. O método 5. A humanidade da humanidade. A identidade humana. Tradução de Juremir Machado da Silva. Porto Alegre: Sulina, 2002.

NÓVOA, António. (Org.). Vidas de Professores. Coleção Ciências da Educação, Portugal: Porto Editora, 1992.

PEREIRA, V. Marcos. Nos supostos para pensar formação e autoformação: a professoralidade produzida no caminho da subjetivação. In: FRAZÃO, C. et al. Ensinar e aprender: sujeitos, saberes e pesquisa. 2. ed. Rio de Janeiro: Dp\&A., 2001, p. 23-41.

PEREIRA, V. Marcos. Estética da professoralidade. Um estudo crítico sobre a formação do professor. Santa Maria: Ed. da UFSM, 2013. 
ROSA, João Guimarães. Tutaméia. Terceiras Estórias. Rio de Janeiro: José Olympio, 1967.

ROSA, João Guimarães. Grande sertão: veredas. São Paulo: Círculo do Livro. Ed. Nova Fronteira. 1986.

SACRISTÁN, José Gimeno. Consciência e acção sobre a prática como libertação profissional dos professores. In: NÓVOA A. Profissáo Professor. 2. ed. Porto: Porto Editora, 1995, p.63-92.

SERPA, Felippe. Rascunho digital. Diálogos com Felippe Serpa. Salvador. Edufba, 2004.

SMYTH, John. Teacher's work and the politcs of reflection. In: American Educational Research Journal, v. 29, N 2, 1992, p. 267 - 300.

VEIGA-NETO, A. Olhares... In: COSTA. M. V. (Org.) Caminhos investigativos. Novos olhares na pesquisa em Educação. Sáo Paulo: DP\&A editora. 2002, p. 23-38. 